\title{
Scaling the heights: the background and development of a novel remote highwall scaling machine for use at the Savage River Mine
}

\author{
MS Anderson Grange Resources Ltd, Australia
}

C Johnson Jayben Group, Australia

\begin{abstract}
The Savage River Mine is located in the rugged northwest of Tasmania and provides high quality Magnetite ore for pelletising. The mine is in a high rainfall area and is currently over $400 \mathrm{~m}$ deep with an inter-ramp slope angle of over $62^{\circ}, 30 \mathrm{~m}$ high batter faces and $12 \mathrm{~m}$ wide catch benches. An unfavourable joint set dipping into the pit at around $45^{\circ}$ frequently results in poor crest retention and loss of access along the benches. The high rainfall and life-of-mine dilation have resulted in recent rockfalls from this wall ranging from $5 t$ to $10,000 t$. While these rockfalls have been retained over a number of benches, the resulting rill often fills the catch berms, increasing the likelihood that any subsequent rockfall in this area will reach the work area below.

To address this risk a remotely controlled scaling machine has been developed as a joint project between Grange Resources and Jayben Group, Australia. It is remotely controlled and capable of descending approximately $90 \mathrm{~m}$ over a vertical face. This provides access to remediate unstable sections of batter and to clear failed rill material from otherwise inaccessible benches to re-establish catch capacity. The machine uses world first, real time 3D image processing technology to provide the operator and Geotechnical Engineers advanced mapping and structural data and the ability to accurately place scaling tools to best effect.

Preliminary testing of the prototype has been successful, demonstrating excellent stability on even vertical batters but hi-lighted the need to further improve the wireless communication system and some hydraulic systems to address issues identified during testing.
\end{abstract}

Keywords: batter scaling machine, highwall scaling, rockfall remediation, remote, restoring catch bench capacity, Jayben $\mathrm{S6O}$ Scaler, clean up, post rockfall

\section{Introduction}

The Savage River Mine is located in northwest Tasmania and has been producing Magnetite for steelmaking for over 50 years. The magnetite ore is concentrated on site and delivered as a slurry to a pelletising facility on the coast via an $85 \mathrm{~km}$ long pipeline from where it is shipped to customers.

Through the life of the operation there have been no less than six pits along the $6 \mathrm{~km}$ strike length of the orebody and numerous large-scale wall failures. By far the largest of these pits is the North pit. It is currently $1,900 \mathrm{~m}$ long, 1,000 $\mathrm{m}$ wide and $400 \mathrm{~m}$ deep. The pit is characterised by a high-grade massive magnetite orebody in a weak schistose host and bounded to the east by a steeply dipping fault with much stronger calcite-chlorite schist (amphibolite) to the east. This results in an oval shaped pit with inter-ramp slope angles (IRA) approaching $36^{\circ}$ on the western side of the pit and $63^{\circ}$ to the east. 


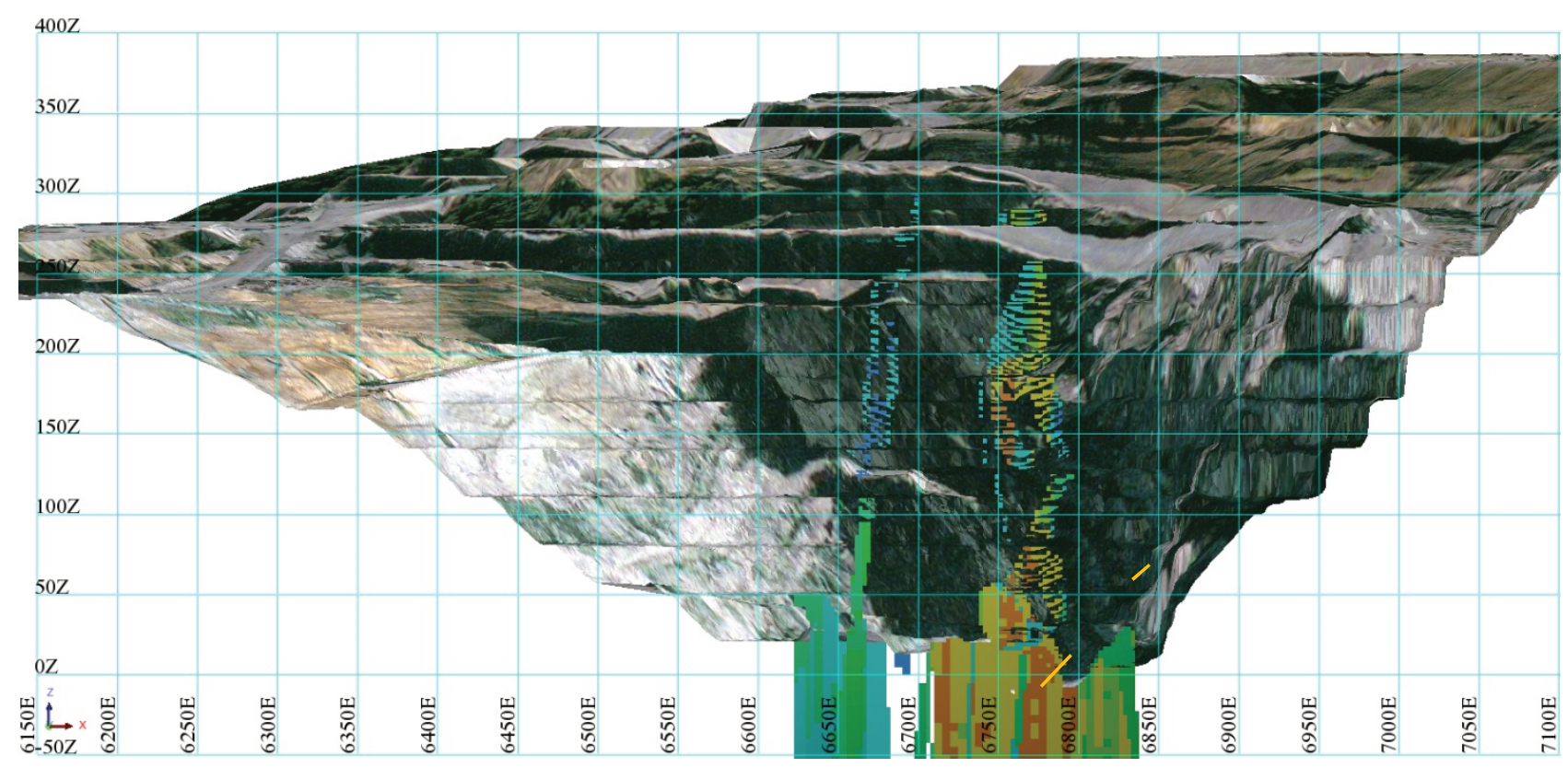

Figure 1 Typical cross-section of North Pit 9700N

\section{Rockfall history and experience}

Over the last ten years the North Pit has experienced a large number of rockfalls and rock slides ranging in size from single rocks under $100 \mathrm{~kg}$ through to inter-ramp failures of close to 1,000,000 t. These failures are largely due to the highly sheared nature of the rock mass and the high rainfall environment that the mine is located in with over two metres average annual rainfall. All of the larger failures have been detected successfully well in advanced by slope stability radar monitoring systems employed at Savage River since 2007 (MacQueen et al. 2013). The radar systems however have not been successful in detecting the small, sometimes brittle failures experienced on the steep east wall of the pit. It is these rockfalls that are of particular concern as the alarm system is less effective. More traditional operational controls such as exclusion zones and catch benches, along with vertical batters to reduce horizontal momentum have been the primary controls used in the past.

To supplement and reinforce these controls remotely controlled equipment has been in use at the base of the east wall since 2006 (Hutchison \& Widelski 2007). Since that time the fleet of remote equipment has been developed and expanded to include dozers (Caterpillar D10T) for clean-ups, excavators for batter scaling and working below large unstable rill slopes (Hitachi EX1200 and EX1800), Drill rigs used on all trim shots (Sandvik Titon 600 and Epiroc D65), a customised horizontal de-pressurisation drill rig and a Merlo telehandler to provide the capability to charge and stem drillholes remotely. This enables a true $20 \mathrm{~m}$ exclusion zone to be used at the toe of the highwall to ensure operator safety.

Since 2006 the site has been collecting data on all rockfalls across the site as reported by personnel or detected through radar monitoring and laser scanning of walls in the active pits. All these events are recorded in the 'Rockfall Register' along with other related data such as rainfall, relationship to blasting, size, runout distance and whether or not the movement was predicted in advance by the slope stability radar systems. Figure 2 shows the number of rockfalls occurring on the east wall that were too small or rapid to be predicted by slope stability radar and Figure 3 shows the runout distance of those rockfalls. Both graphs are categorised by rockfall potential consequence from insignificant (small rockfall entirely retained on the first berm) through to catastrophic (the potential for a fatality). The data also identifies high risk times for rockfall like immediately after blasting and during rainfall events. This correlation has allowed administrative controls to be developed to further reduce risk by closing high risk areas of the pit completely during these times. 


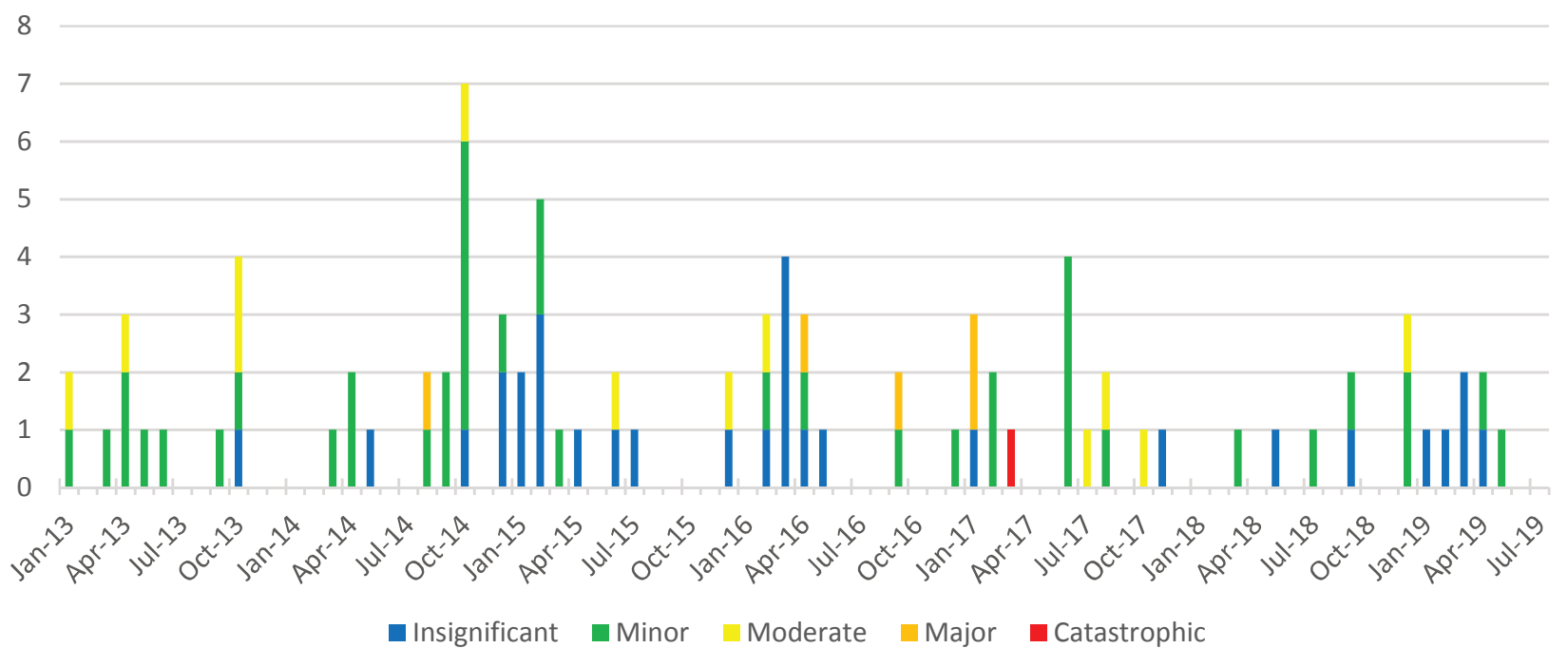

Figure 2 Rockfall frequency for height greater than one bench $(30 \mathrm{~m})$

During 2016, a trend emerged of increasing frequency and runout distance of un-detected rocks. These were mostly small scats or clusters up to $100 \mathrm{~kg}$ that were coming to rest outside the exclusion zone and posing a risk to personnel. It was determined that the seed location for these rocks was around $260 \mathrm{~m}$ Reduced Level (RL, height above sea level), about $90 \mathrm{~m}$ above the working bench. This height coupled with areas of low catch capacity across multiple berms led to rocks gaining horizontal momentum and projecting further into the working area than had previously been experienced.

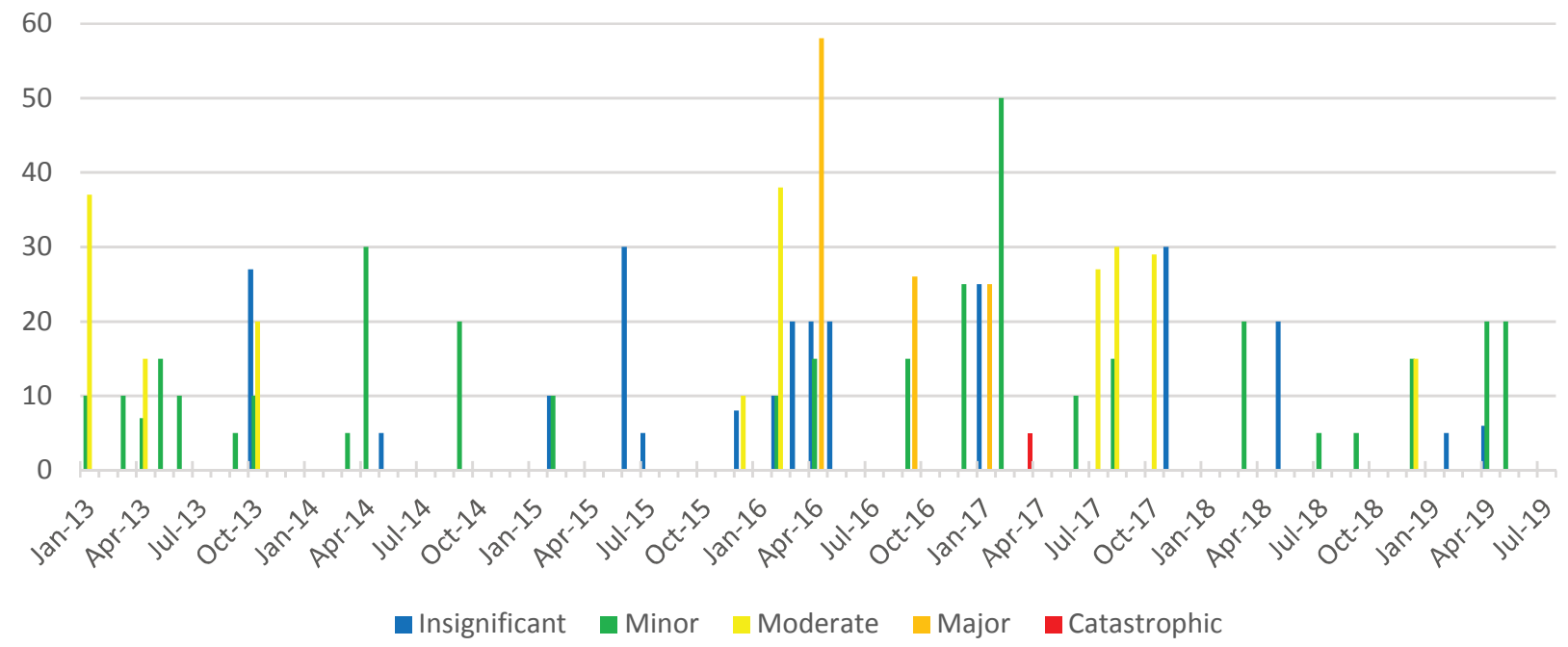

Figure 3 Rockfall runout distance $(\mathrm{m})$ for height greater than $30 \mathrm{~m}$

The two main causes of poor catch capacity in this section of wall were identified as crest loss through the intersection of the ski-jump joint set and the remaining rill slopes from previous rockfalls. A $30 \mathrm{t}$ long reach excavator was trialled to access along the berms from the south in an attempt to reach areas where small rockfalls had over time filled the berms to the point that no effective catch capacity remained (Figure 4b). While this met with some limited success, there were many areas that could not safely be accessed using conventional equipment of this type. 


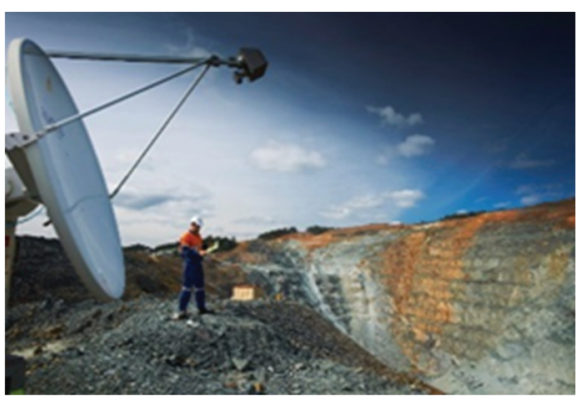

(a)

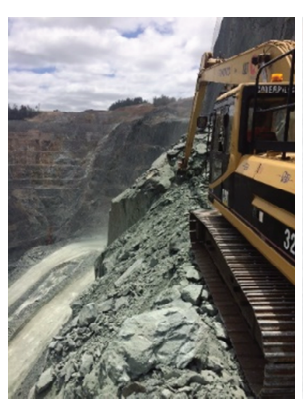

(b)

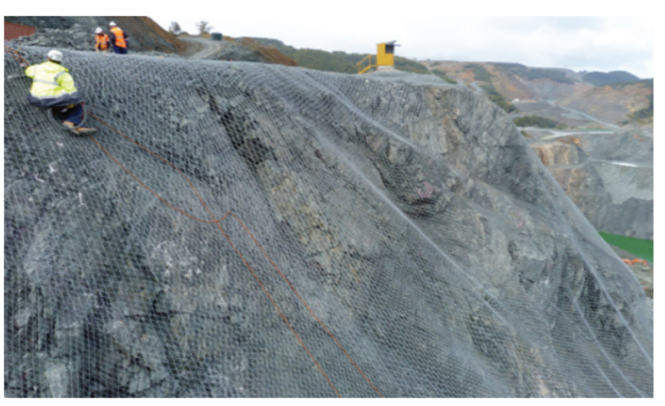

(c)

Figure 4 Photos of North Pit: (a) Radar monitoring; (b) Long reach excavator clearing berms; (c) Drape mesh installation

Despite the addition of a geotechnical berm at the $170 \mathrm{RL}$ where the width was increased from $12 \mathrm{~m}$ to $20 \mathrm{~m}$, and the installation of a section of $30 \mathrm{~m}$ high drape mesh as used with great success previously (Hutchison et al. 2013) to reduce the incidence of rockfall from the $260 \mathrm{RL}$ crest (Figure 4c), isolated rockfalls continued. Following a further incident in January and 2D modelling (Figure $5 \mathrm{a}$ and $5 \mathrm{~b}$ ), the haul road below this section of wall was closed and a specialist rope access team engaged to manually scale the batters between $260 \mathrm{~m}$ $\mathrm{RL}$ and $170 \mathrm{~m} \mathrm{RL}$ using pry bars and air-bags. This removed the loose rocks and wedges identified and sought to re-establish the catch capacity on the $230 \mathrm{~m}$ and $200 \mathrm{~m} \mathrm{RL}$ berms. It was anticipated using 2D rockfall modelling (Figure $5 \mathrm{c}$ ) that following the success of this program, a $5 \mathrm{~m}$, high energy rock catch fence could be installed on the $170 \mathrm{~m} \mathrm{RL}$ berm, providing protection to the haul ramp and enabling it to be re-opened.

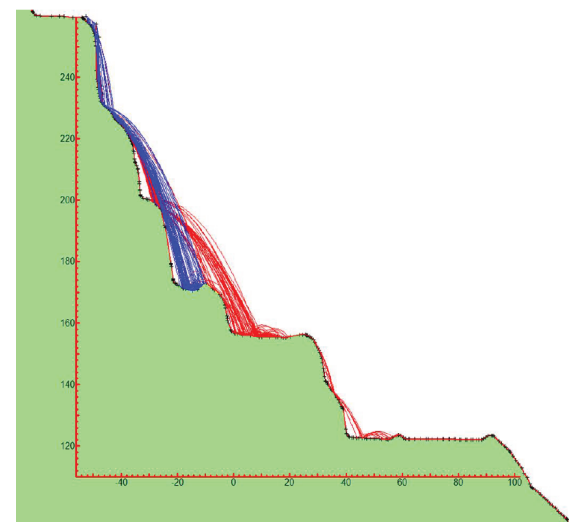

(a)

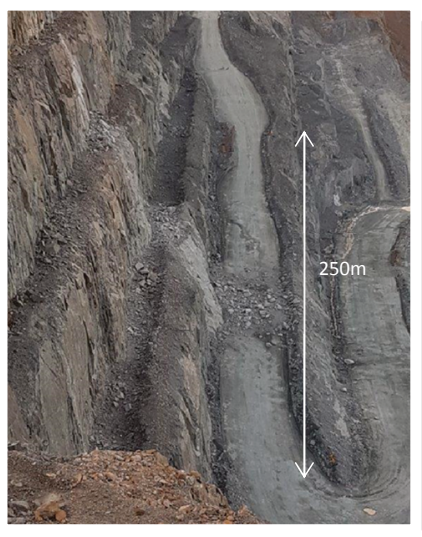

(b)

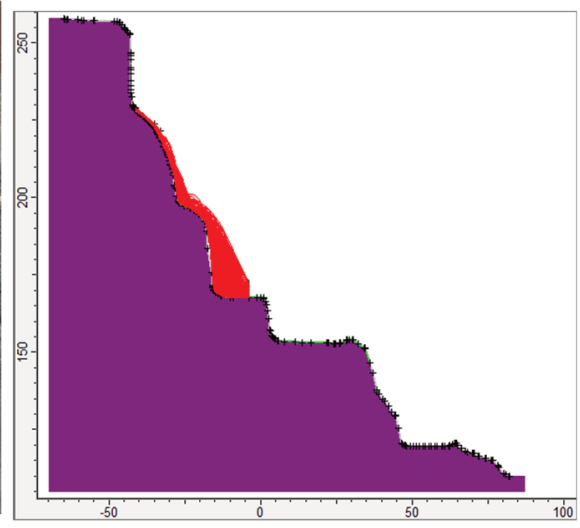

(c)

Figure 5 Analysis of January 2017 rockfall that led to the closure of the 170-140 RL ramp: (a) RocScience RocFall analysis of East Wall without rock catch fence; (b) Photograph of January 2017 failure looking south through the modelled section; (c) RocScience RocFall analysis of East Wall with rock catch fence

Following almost four weeks of intensive scaling by the team and approaching the conclusion of the program, a $40 \mathrm{t}$ rockfall occurred without warning resulting in the tragic loss of one of the scaling team. Plans to install the high energy rock catch fence and re-open the haul road beneath this area were abandoned.

Immediately following the scaling that was completed on the east wall, the incidence of rockfalls in this area was dramatically reduced, as can be seen in Figure 2 . The runout distance of rockfalls occurring with no radar warning also decreased. This demonstrated that scaling of problematic pit highwalls was an effective solution to reduce rockfall risk, however the risk to personnel involved in this process was too great.

Following the scaling program, the implementation of drone-based photogrammetry and improvements in laser scanning and radar technology has continued to allow areas to be identified that could be remediated and reduce disruption to operations and risk to personnel if they could be removed. 


\section{Remotely controlled highwall scaling machine}

During 2017 ideas for a specialised machine that would be able to access areas identified for geotechnical remediation and clear berms of accumulated rill material were developed. The idea was to have a small, remotely controlled excavator with crane style winches to allow it to 'abseil' down the wall in a similar way to the rope access team. The advantage perceived at the time was that this would put no personnel at risk and would also provide far more flexibility and breakout force than a human team could bring to bear, particularly in regard to re-establishing catch capacity on berms and removing accumulated rill.

Toward the end of 2017 two local engineering firms were asked to put together conceptual proposals to design a machine that could fulfil the following requirements:

- Safely remove boulders and rock wedges from vertical batters on a pit wall and remain stable for short over-hangs.

- Access berms from above, establish a level pad and progressively side-cast rill from the berm to re-stablish effective catch capacity.

- Self-support and able to reach heights of 70-90 m unaided with the ability to increase this vertical operating height if required.

- Provide rock breaking, rock bucket, mud bucket and ripper tooth attachments for scaling and berm clearing.

- Multiple redundant systems to ensure the machine would not be disabled or become stranded during operation.

Both engineering companies submitted valid concepts and the site team were further encouraged by a small number of photos found on the internet showing a similar machine being used in Japan to clear landslides.

Early in 2018, the team arranged a visit to the contracting company that had developed the system (Dachang Construction Co., Ltd). While it was not possible to view any of the equipment operating, it was clear following the visit that while the technology in use was similar, it was mostly used with an operator in the cab of the machine during operation and at significantly shallower slope angles. A line of sight remote system had been developed for particularly high-risk situations, but the system relied heavily on the operator with no safety interlocks, machine guidance, video cameras or feedback systems to assist the operator.

During the remainder of 2018 a detailed engineering process was undertaken to continue to develop and hone the concept and following a stage-gate review, construction of a prototype was started early in 2019.

The prototype (Figure 6a) is based on a Caterpillar 308 E2CR excavator that has been heavily modified to allow it to operate both horizontally and at any angle through to fully vertical. The operator cabin has been removed and the track frame lengthened to provide a mounting point for twin hi-torque winches. Each winch and cable are independently capable of supporting and retrieving the $18 \mathrm{t}$ machine in the event of a failure of the other winch. The power module is protected by a modified counterweight when operating vertically and by toughened composite panels elsewhere to reduce mass. A $360^{\circ}$ tilt rotator hitch allows for precise positioning of the tools for scaling and improved breakout force geometry. Initially the machine will be supported using grouted rock anchors with a specialised braking system to reduce the shock loading forces during a fall or emergency event. 


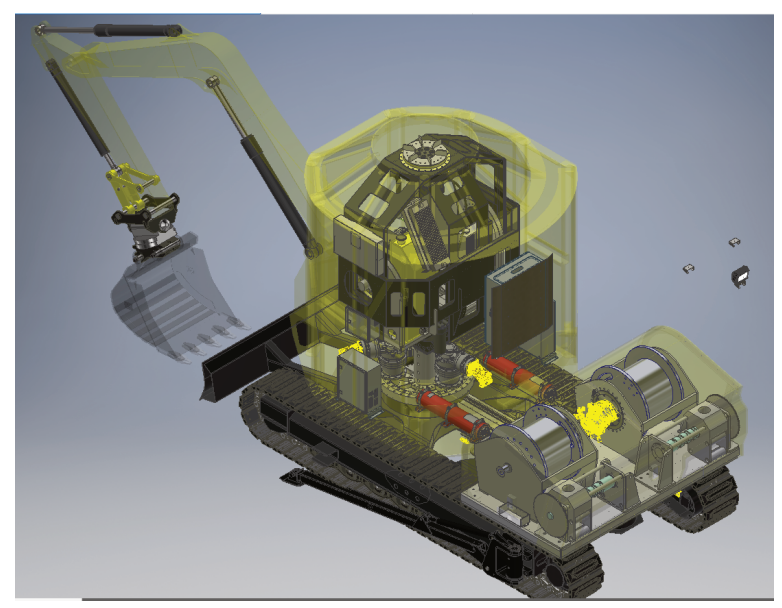

(a)

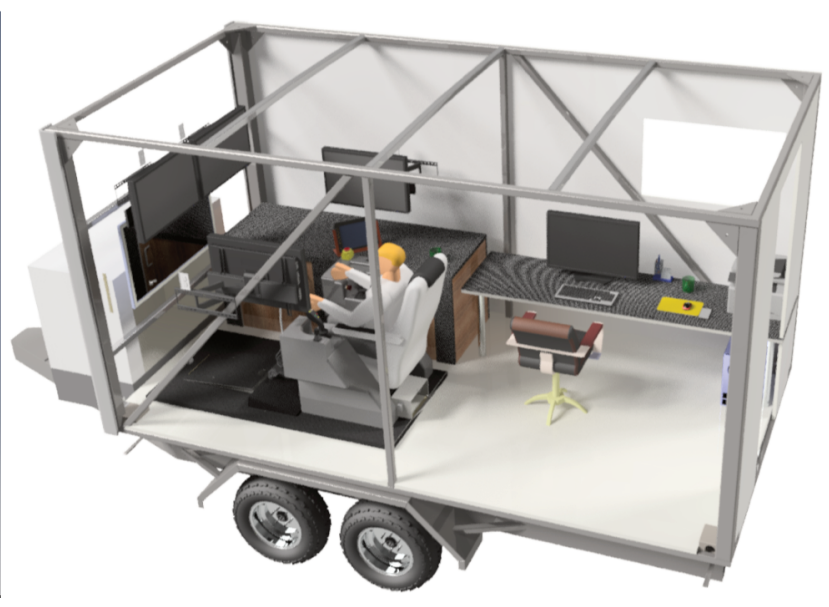

(b)

Figure 6 (a) Schematic of remote scaling machine; and (b) Schematic of operator station

Consideration has been given to maintenance with a portable remote-control system and safety interlocks to limit the range of movement while providing access to key areas for troubleshooting and servicing.

The machine operator is provided with a range of aids, including an array of cameras, overload protection for the hydraulic and electrical systems, and an advanced 3D camera system that dynamically provides depth perception and 3D mapping in real time. This data is also recoded to the operator station (Figure 6b) to allow site geotechnicians to review the point cloud and images generated by the 3D camera system on each deployment independently to highlight areas for further attention.

\section{$4 \quad$ Field testing}

During December 2019 initial field testing was completed at a nearby quarry. The scaling machine was anchored with a Caterpillar D9 dozer (Figure 7a) and successfully transitioned over the crest and down the near vertical batter face (Figure $7 \mathrm{~b}$ ) and returned to the starting position using the maintenance remote kit. The machine was far more stable than expected and was able to quickly and effectively remove loose material from the batter face without any appreciable movement of the tracks on the wall. Winch performance was also impressive and provided plenty of torque to raise and lower the machine when working on the wall and to recover all of the way back to the bench.

The range of the remote operator station (Figures $7 \mathrm{c}$ and $7 \mathrm{~d}$ ) was tested to approximately $200 \mathrm{~m}$ but interference and signal strength proved to be a problem. As such the remainder of the test was done using the hand held maintenance remote system. The wireless remote system will be reviewed and improved prior to the next round of testing.

With the track extension required to allow the mounting of the winches, the machine was found to be much less manoeuvrable on the bench than had been anticipated. This was exacerbated by the boom lift cylinders having insufficient power to lift the front of the machine off the ground with the increased mass and leverage of the longer tracks. This will be addressed through an upgrade to the track motors to increase the torque available to walk the tracks differentially to steer the machine on the flat and changing the boom hydraulic system from a single cylinder to twin cylinders either side of the boom.

Finally, the hydraulic slew joint used to allow a $360^{\circ}$ slew function, failed during use with the mechanical seals blowing and allowing hydraulic fluid to escape from the system. This component would usually be compressed by the mass of the machine, however due to the unique gimbal mounted engine module of this machine, the hydraulic union is used in a much less confined application. A custom manufactured union has been designed and will provide significantly increased clamping force to prevent further failures of this type. 
These modifications are all underway as at January 2020 with further field testing planned by then end of March and deployment to site expected in mid-2020.

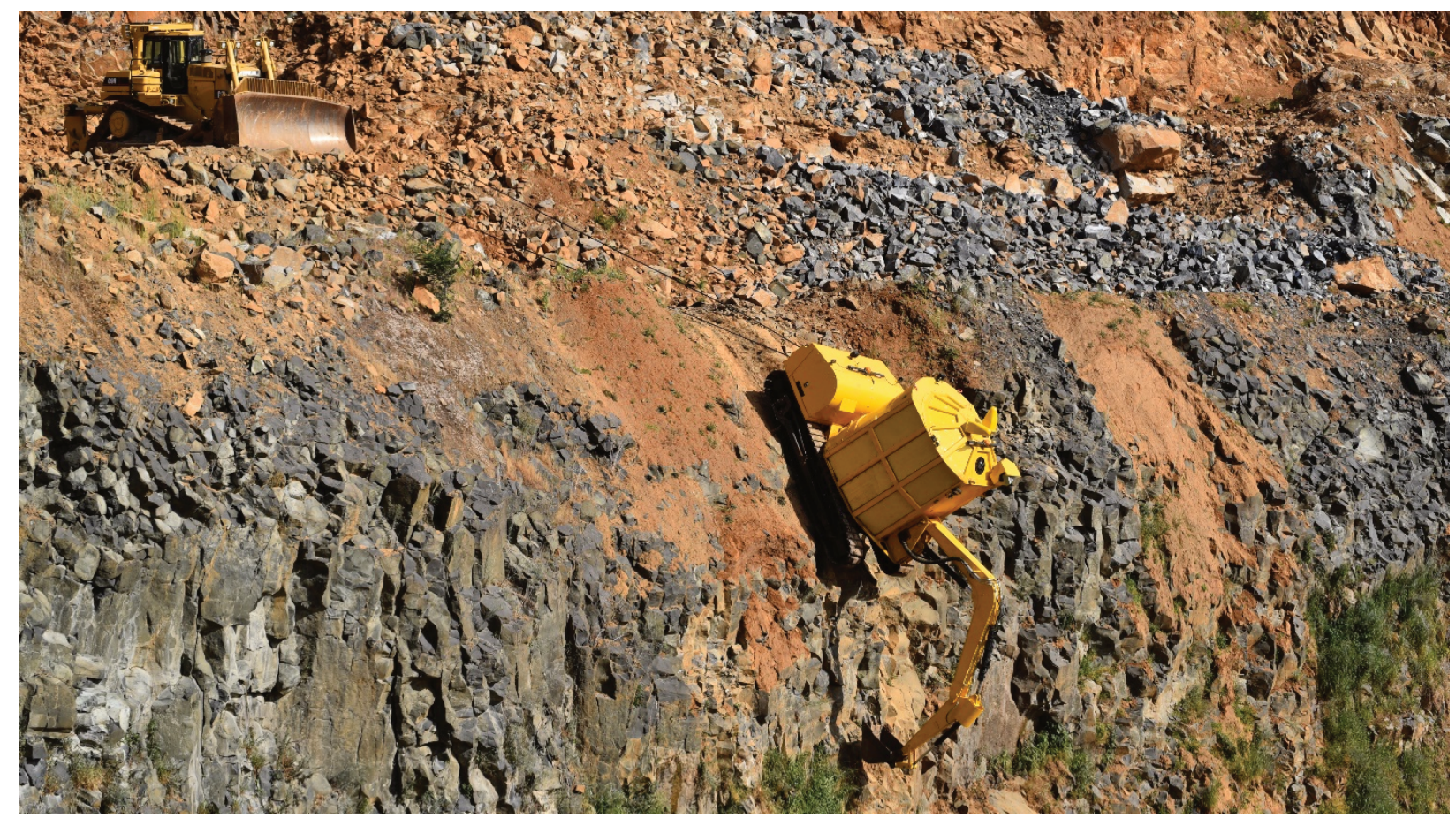

(a)

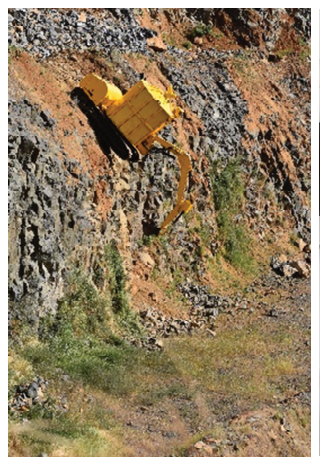

(b)

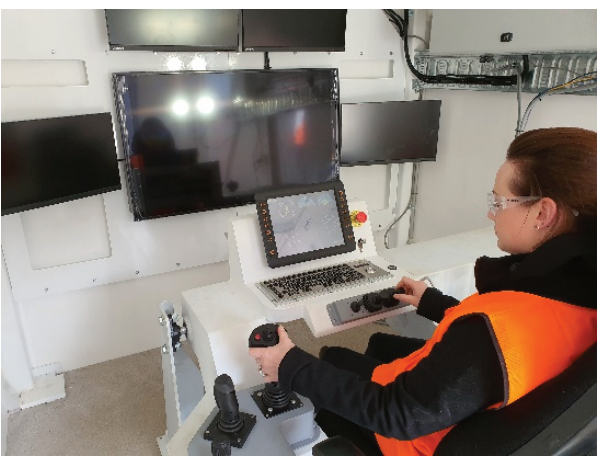

(c)

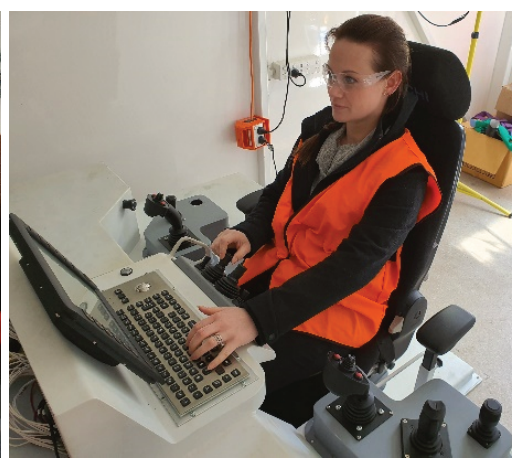

(d)

$\begin{array}{ll}\text { Figure } 7 & \text { (a) and (b) Remote highwall scaling machine in operation; (c) and (d) Operator station }\end{array}$

\section{$5 \quad$ Future developments}

The highwall scaling machine provides some unique areas for further developments. As the machine is self-contained and provides mechanical, hydraulic and electrical power systems, it can deliver tools that were previously too heavy or bulky to locations that were previously too difficult or dangerous. Through the process of designing and building the prototype machine, several improvements have already been identified.

Software updates are planned to further enhance the operator assistance package to automate and streamline complex manoeuvres such as transitioning over a pit crest or from a batter to a horizontal berm. It is also envisioned that with high resolution images and detailed system information being collected, a simulation package will be developed to assist in operator training and developing operating techniques without putting the machine at risk. The opportunity to use the operator station de-coupled from the machine as a simulator training aid has also been identified for future development. 
Hydroscaling has been used previously at Savage River with mixed results. It seems most effective when large volumes of high-pressure water can be applied with a degree of precision. The highwall scaling machine seems to be an ideal tool for accurately positioning a water jet very close to the required area without putting personnel or equipment at risk. Plans are underway to provide a water cannon type with a standard quickhitch attachment and hose guides to allow water to be pumped from above. Similarly, a rotary broom attachment may provide the ability to clean otherwise inaccessible areas of smaller rock and debris to prevent it washing off the wall during rainfall events.

It is likely that some large wedges in batters or boulders on berms will be too big for the rock hammer attachment to breakup and dislodge. A small drifter arm with a carousel containing packaged explosive charges and wireless detonator seems to be an ideal way to deliver and initiate charges to the keel of a wedge to remove it from a batter in a controlled manner. This technology is commercially available and seems a likely progression.

Rock reinforcement has also been considered. Using the machine to install mesh and pins over a large area seems a possibility, as does the attachment of a shotcreting head to stabilise areas that would be otherwise inaccessible. In a similar way it could be used to spread mulch over rock dumps and pit walls for revegetation on mine closure.

\section{Broader industry application}

Jayben has begun to investigate the wider market for a machine of this type through market research, focused on liaising with geotechnical engineering professionals together with mining houses. The following areas have been identified as potential areas of interest in a range of applications outside the direct application in open pit mining including variants for the following applications:

- Rail road wall maintenance - thousands of kilometres of mining rail is subjected to rockfall events which create unsafe environments and reduce train productivity. A rapid response capability can improve train productivity.

- Alpine road maintenance - safe access in difficult to access mountainous terrain.

- Mud slip rehabilitation and clean up - access to mud slide/land slip areas which are not safe for human access or otherwise too steep for conventional equipment to access.

- Military forward projection - assistance to open up difficult terrain for more conventional military armoured vehicles and mobile equipment.

- Underground stope work - removal of rock hangs ups etc.

- Underground conveyor maintenance - travelling down steep conveyor systems to clear blockages.

- Underground ventilation raisebore and orepass tunnel maintenance.

\section{Conclusion}

The ability to actively remediate areas identified by slope stability monitoring is a significant advance for both safety and production. While still early days in the operation of the remote highwall scaling machine, early signs are promising, particularly in the area of re-establishing catch capacity on berms following rockfall or blasting activities with no other viable solutions in this area. This type of equipment also has the potential to significantly reduce the impact and cost in remediating large rockfalls and in the future could be considered as an alternative to a costly cutback or unplanned geotechnical berm.

\section{Acknowledgements}

Grange wish to acknowledge the ongoing collaborative relationship with Jayben Group, Australia in developing the highwall scaling machine for use at Savage River. 
The author would also like to thank Mr Okamoto of Dachang Construction Co., Ltd. for hosting a visit to his facility and providing the benefit of his experiences working on steep slopes over 30 years.

\section{References}

Hutchison, BJ \& Widelski, M 2007, 'Rockfall management at Savage River Mine', in Y Potvin (ed.), Proceedings of the 2007 International Symposium on Rock Slope Stability in Open Pit Mining and Civil Engineering, Australian Centre for Geomechanics, Perth, pp. 379-392.

Hutchison, BJ, Macqueen, GK, Dolting, SL \& Morrison, AT 2013, 'Drape mesh protection at the Savage River Mine, Tasmania', in PM Dight (ed.), Proceedings International Symposium on Slope Stability in Open Pit Mining and Civil Engineering, Australian Centre for Geomechanics, Perth, pp. 1345-1358.

Macqueen, GK, Salas, El \& Hutchison, BJ 2013, 'Application of radar monitoring at the Savage River Mine, Tasmania', in PM Dight (ed.), Proceedings of the 2013 International Symposium on Slope Stability in Open Pit Mining and Civil Engineering, Australian Centre for Geomechanics, Perth, pp. 1345-1358, https://doi.org/10.36487/ACG_rep/1308_70_Macqueen 
